\title{
Assessing water resources in China using PRECIS projections and a VIC model
}

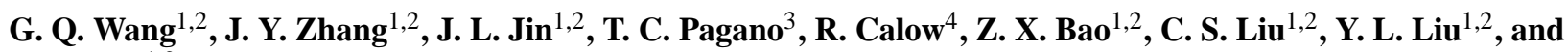 \\ X. L. Yan ${ }^{1,2}$ \\ ${ }^{1}$ State Key Laboratory of Hydrology-Water Resources and Hydraulic Engineering, Nanjing Hydraulic Research Institute, \\ Nanjing 210029, China \\ ${ }^{2}$ Research Center for Climate Change, Ministry of Water Resources, Nanjing 210029, China \\ ${ }^{3}$ CSIRO Land and Water, Melbourne, Victoria, Australia \\ ${ }^{4}$ Overseas Development Institute, London, SE1 7JD, UK \\ Correspondence to: G. Q. Wang (gqwang@nhri.cn)
}

Received: 17 June 2011 - Published in Hydrol. Earth Syst. Sci. Discuss.: 25 July 2011

Revised: 24 November 2011 - Accepted: 2 January 2012 - Published: 25 January 2012

\begin{abstract}
Climate change is now a major environmental and developmental issue, and one that will increase the challenge of sustainable water resources management. In order to assess the implications of climate change for water resources in China, we calibrated a Variable Infiltration Capacity (VIC) model with a resolution of $50 \times 50 \mathrm{~km}^{2}$ using data from 125 well-gauged catchments. Based on similarities in climate conditions, soil texture and other variables, model parameters were transferred to other areas not covered by the calibrated catchments. Taking runoff in the period 1961-1990 as a baseline, we studied the impact of climate change on runoff under three emissions scenarios, A2, B2 and A1B. Model findings indicate that annual runoff over China as a whole will probably increase by approximately $3-10 \%$ by 2050 , but with quite uneven spatial and temporal distribution. The prevailing pattern of "north dry and south wet" in China is likely to be exacerbated under global warming.
\end{abstract}

\section{Introduction}

Global warming caused by increasing atmospheric concentrations of carbon dioxide and other trace gases has become evident. There is broad consensus that the Earth's surface air temperature increased by about $0.74^{\circ}$ during the last century, with the greatest increases occurring in the 1990s. Moreover, global temperature increases are likely to continue in the $21 \mathrm{st}$ century and will probably be accompanied by changes in precipitation (IPCC, 2007).
In China, changes in surface air temperature are similar to those experienced globally, with increases of about $0.5-0.8^{\circ}$ during the 20 th century, slightly exceeding global temperature change in this period. During the last $50 \mathrm{yr}$ from 1950 to 2000 , air temperature has increased by $1.1^{\circ}$, with the warmest decade occurring in the 1990s. Northeast China, north China and northwest China experienced significant warming in terms of annual average temperatures, with most warming occurring in winter and spring, as expected. In contrast, there has been no significant long-term change in country-averaged annual precipitation. However, an obvious drying trend in the Yellow River basin and significant increase in rainfall for the Yangtze River basin were detectable over the last 50 years of the 20th century (Ding et al., 2006). Global warming is likely to change precipitation patterns and will probably raise the frequency of extreme events.

Climate change and greater climate variability are expected to alter the timing and magnitude of runoff, with significant implications for water resources, water infrastructure and water resources management. Competition for water at different scales, and between different uses and users, is increasing rapidly; floods and drought remain major economic as well as social issues; and environmental issues around water quality and quantity rank high amongst public (and political) concerns. Developing a better understanding of the impact of climate change on water systems in China is therefore a high priority.

The effects of climate change on water resources have been widely investigated and documented throughout the world. Scientists have debated the application of climate 
models to this problem; some have claimed that, due to large uncertainties, climate models are not suitable for assessing water resources, and that it is not realistic to expect the level of accuracy required for adaptation-type analysis (Kiem et al., 2011; Kundzewicz et al., 2010), while others argue that model projections of future climate change are still useful despite their large uncertainties. Many studies have assessed water resources using projections from climate models to drive rainfall-runoff models, thus estimating runoff and stream flow. Conceptual watershed models are often believed to be useful in assessing the impacts of climate change on regional hydrology (Arnell, 1999; Zhang et al., 2007). Gleick et al. (1987) developed a monthly waterbalance model specifically for climate change impact assessment and addressed the advantage of using conceptual watershed models in practice. Loukas et al. (1996) applied a UBC watershed model to study the effects of climate change on the hydrological regime of two climatically different British Columbia watersheds, the Upper Campbell and Illecilewaet watersheds. Huntington et al. (2006) investigated the relationships between mean annual temperature, annual precipitation and evapotranspiration (ET) for 38 forested watersheds in New England, USA, and concluded climate warming could reduce runoff significantly. Roger et al. (2005) estimated the sensitivity to climate change of mean annual runoff in 22 Australian catchments using selected hydrological models, showing how results varied between models. Using ArcGIS Geostatistical Analyst, Fu et al. (2007) developed a method to study the impacts of climate change on regional hydrological regimes in the Spokane River watershed. This study indicated that a $30 \%$ increase in precipitation could result in a $50 \%$ increase in stream flow; conversely, a $20 \%$ decrease in precipitation could results in a $25-30 \%$ reduction in stream flow. Using a NAM model, Hans et al. (2006) investigated the influence of climate change on river discharge in five major Danish rivers for the future period of 2071-2100, finding a $12 \%$ increase in runoff. In China, Li et al. (2008) projected an approximately 5\% decrease in runoff for the headwater region of the Yellow River with an improved XAJ model and ensemble projections of Global Climate Models (GCMs) used in IPCC AR4. Zhang et al. (2009) assessed hydrological responses of the Yellow River to hypothetical climate scenarios using a snowmeltbased water balance model, demonstrating the role soil and water conservation measures could play in reducing the sensitivity of runoff to climate change.

The Intergovernmental Panel on Climate Change (IPCC) has reviewed and referenced the latest studies on climate change and water resources, ranging from local to continental scales and representing a wide variety of physiographic conditions (IPCC, 2008). Previous studies indicate that stream flow is highly sensitive to changes in precipitation, as well as to changes in temperature. A $10 \%$ change in precipitation, all other things being equal, can result in a $12-25 \%$ change in runoff; a $2^{\circ}$ rise in temperature can lead to a $5-12 \%$ decrease in runoff; and runoff in semi-arid or arid areas is more sensitive to climate change than runoff in humid areas (Zhang et al., 2007, 2009; IPCC, 2008). The majority of studies focus on catchments. Nationwide studies, including those in China, have been rare because of variable climate conditions, land cover, morphology and topography. Nationwide modelling in China has also been limited by the lack of calibrated catchments, which often results in somewhat higher uncertainty for ungauged areas.

The objectives of this study are (1) to assess climate change impacts in China by applying a VIC model at the national level with up to 125 calibrated catchments, (2) to investigate climate change across China by using projections of climate model, and (3) to explore the likely impacts of climate change on water resources.

\section{Data and methods}

\subsection{Description of VIC model}

To assess likely changes in water resources, we needed to better understand changes in the hydrological cycle, especially in evapotranspiration. Energy flux plays a vital role in the hydrological cycle. The Variable Infiltration Capacity (VIC) model is a physically-based hydrological model that can simulate the physical exchange of water and energy among the soil, vegetation and atmosphere in a surface vegetation-atmospheric transfer scheme. The VIC model was developed by Liang et al. (1994) and later improved by Lohmann et al. (1998), and Liang and Xie (2001). Notably, it includes (1) both water-balance and energy-balance parameterization; (2) two types of runoff-yielding mechanisms, based on saturation and infiltration excess; (3) consideration of sub-grid-scale soil heterogeneity; and (4) processes of snow accumulation and melt, as well as soil freezing and thawing. Therefore, we used the VIC model in this study.

The VIC model divides study catchments into grid cells and the soil column of each grid into three layers. The upper two layers, designed to represent the dynamic response of soil to rainfall events, were usually combined into one layer in our modelling. The lower soil layer is used to characterize the behavior of seasonal soil moisture. Three types of evaporation are considered (http://www.hydro.washington. edu/Lettenmaier/Models/VIC/): (1) evaporation from wet canopy; (2) evapotranspiration from dry canopy; and (3) evaporation from bare soil. Stoma resistance is used to reflect the effects of radiation, soil moisture, vapor pressure deficiency, air temperature and other factors in calculations of transpiration from the canopy (Lu et al., 2010; Xie et al., 2007).

The total runoff estimates consist of surface flow and base flow. Surface flow, including infiltration excess flow and saturation excess flow, is generated in the two top layers only. 
In order to consider the heterogeneity of soil properties, we employed a soil storage capacity distribution curve and an infiltration capacity curve. The double curves are individually described as power functions with a parameter $B$ as the exponent. Base flow occurs in the lowest layer only and is described using the ARNO method (Habets, 1999). A onedimensional Richards equation is used to describe the vertical soil moisture movement (Lu et al., 2010; Xie et al., 2007). Estimates of surface flow and base flow are mathematically described as follows:

$Q_{d}=\left\{\begin{array}{cc}P+W_{0}-W_{0}^{\max } & I_{0}+P \geq I_{m} \\ P+W_{0}-W_{0}^{\max }\left[1-\left(1-\frac{I_{0}+P}{I_{m}}\right)^{1+B}\right] & I_{0}+P \geq I_{m}\end{array}\right.$

$Q_{b}=\left\{\begin{array}{cc}\frac{D_{s} \cdot D_{m}}{W_{s} \cdot W_{2}^{c}} \cdot W_{2}^{-} & 0 \leq W_{2}^{-} \leq W_{s} \cdot W_{2}^{c} \\ \frac{D_{s} \cdot D_{m}}{W_{s} \cdot W_{2}^{c}} \cdot W_{2}^{-}+\left(D_{m}-\frac{D_{s} \cdot D_{m}}{W_{s}}\right) \cdot\left(\frac{W_{2}^{-}-W_{s} \cdot W_{c}^{c}}{W_{2}^{c}-W_{s} \cdot W_{2}^{c}}\right)^{2} & W_{2}^{-}>W_{s} \cdot W_{2}^{c}\end{array}\right.$

Where $Q_{d}$ is surface flow, $Q_{b}$ is base flow, $P$ is precipitation, $W_{0}$ is initial soil moisture of the upper soil layer, $W_{0}^{\max }$ is maximum soil moisture of the upper soil layer, $I_{0}$ is initial infiltration rate, $I_{m}$ is maximum infiltration rate, $B$ is variable infiltration curve parameter, $D_{m}$ is maximum daily base flow, $D_{s}$ is the fraction of $D_{m}$ in which non-linear base flow occurs, $W_{2}^{c}$ is maximum soil moisture in the lower soil layer, $W_{2}^{-}$is initial soil moisture in the lower soil layer, and $W_{s}$ is the fraction of $W_{2}^{c}$ in which non-linear base flow occurs. The maximum soil moisture in each soil layer $\left(d_{1}, d_{2}\right.$ and $\left.d_{3}\right)$ is estimated based on soil texture and soil layer thickness.

There are many measures available to evaluate model performance, including coefficient of correlation $(R)$, NashSutcliffe efficiency coefficient (NSE), root-mean-squared error (RMSE) and mean absolute percentage error (MAPE), among which the Nash and Sutcliffe efficiency criterion is a normalized statistic reflecting the relative magnitude of the residual variance compared to the measured data variance (Nash and Sutcliffe, 1970; Wang et al., 2009). It is easy to compare the performance of hydrological models for different catchments with NSE. For the purpose of hydrological simulation, we needed not only a good fit between observed and simulated runoff series, but also a good balance of total water mass. Therefore, the NSE criterion and the relative error of volumetric fit (RE) were both employed as objective functions to calibrate the model. A good simulation result will have NSE close to 1 and RE approaching 0 .

\subsection{Data set}

The VIC model requires data on soils, vegetation and hydrometeorology. Vegetation data sets are derived from Advanced Very High Resolution Radiometer (AVHRR), which provides information on global land classification at $1 \mathrm{~km}$ resolution. Vegetation parameters, including architectural resistance, minimum stomata resistance, leaf-area index, albedo, roughness length and zero-plane displacement, are derived mainly from the Land Data Assimilation System (LDAS) (Hansen, et al., 2000; Xie et al., 2010). The classification of soil texture is based on global 5-min data provided by the National Oceanic and Atmospheric Administration (NOAA) hydrology office. The values for soil-related parameters, including porosity, saturated soil potential and saturated hydraulic conductivity, are derived from the work of Cosby et al. (1984) and Raw et al. (1976).

The forcing data used for the VIC model include daily precipitation, air temperature, solar radiation, vapor pressure and wind velocity. Due to the limited coverage of meteorological data, only daily precipitation and daily maximum and minimum air temperatures are used, while other forcing terms are given default values. There are 2650 meteorological stations in China with available data (among which 673 stations are from the Chinese Meteorology Administration (CMA) and 1977 stations are from the Ministry of Water Resources (MWR)). Daily precipitation and daily maximum and minimum air temperatures from 1955 to 2008 were collected to drive the VIC model.

As the VIC model is run through grid cells, the whole of China is divided into 4160 cells with a resolution of $0.5^{\circ} \times 0.5^{\circ}$. There are many gridding methods available in the literature, including the Method of Inverse Distance to a Power, the Kriging method, the Minimum Curvature method, the Nearest Neighbor method, the linear distance weighted interpolation method, etc. Zhang et al. (2007) evaluated the performance of different gridding methods by comparing areal average precipitations and temperatures derived from gridding data and recorded data from meteorological stations respectively, at different scales, and found the linear distance weighted interpolation method performs well, with relative errors of annual precipitation ranging from $-2.4 \%$ to $3.8 \%$ and absolute errors of annual mean temperature ranging from $-0.31^{\circ}$ to $0.26^{\circ}$. Using this method, we interpolated meteorological data at 2650 stations for each grid cell. Daily discharges at the outlet stations of 125 sub-basins in ten major water regions were used to calibrate and validate the VIC model, and daily discharges at 15 key hydrometric stations on major rivers with large drainage areas were employed to test model performance in large-scale hydrological simulations. The major river systems in China and the locations of 125 hydrometric stations on sub-catchments are shown in Fig. 1. Table 1 provides information on the characteristics of the 15 key hydrometric stations on the major rivers.

The selected sub-catchments vary in size and cover different soil, vegetation, morphology, climatic and hydrological characteristics. The area of drainage basins ranges from $284 \mathrm{~km}^{2}$ to $87453 \mathrm{~km}^{2}$, annual precipitation ranges from $326-1802 \mathrm{~mm}$, and altitude ranges from $41 \mathrm{~m}$ to $4452 \mathrm{~m}$. Annual average air temperature varies from -3.6 to $22.8^{\circ}$. 
Table 1. River basins used to test model performance.

\begin{tabular}{cllrrrr}
\hline No. & River & Gauging site & Longitude & Latitude & Area $\left(\mathrm{km}^{2}\right)$ & Data series \\
\hline 1 & Songhuajiang River & Yilan & $129.55^{\circ}$ & $46.33^{\circ}$ & 491706 & $1956-2008$ \\
2 & Songhuajiang River & Ha'erbin & $126.58^{\circ}$ & $45.77^{\circ}$ & 389769 & $1956-2008$ \\
3 & Liaohe River & Tieling & $123.83^{\circ}$ & $42.33^{\circ}$ & 120764 & $1956-2008$ \\
4 & Haihe river & Luanxian & $118.75^{\circ}$ & $39.73^{\circ}$ & 44100 & $1956-2008$ \\
5 & Haihe River & Shixiali & $114.62^{\circ}$ & $40.22^{\circ}$ & 23627 & $1956-2008$ \\
6 & Yellow River & Lanzhou & $103.82^{\circ}$ & $36.07^{\circ}$ & 229224 & $1956-2008$ \\
7 & Yellow River & Huaxian & $109.77^{\circ}$ & $34.58^{\circ}$ & 106498 & $1956-2008$ \\
8 & Huaihe River & Wangjiaba & $115.60^{\circ}$ & $32.43^{\circ}$ & 30630 & $1956-2008$ \\
9 & Huaihe River & Wujiadu & $117.38^{\circ}$ & $32.93^{\circ}$ & 121330 & $1956-2008$ \\
10 & Yangtze River & Shigu & $99.93^{\circ}$ & $26.90^{\circ}$ & 244489 & $1956-2008$ \\
11 & Yangtze River & Beipei & $106.42^{\circ}$ & $29.85^{\circ}$ & 156142 & $1956-2008$ \\
12 & Yangtze River & Huangzhuang & $112.58^{\circ}$ & $31.20^{\circ}$ & 142056 & $1956-2008$ \\
13 & Pearl River & Tian'e & $107.17^{\circ}$ & $25.00^{\circ}$ & 105535 & $1956-2008$ \\
14 & Pearl River & Gaoyao & $112.47^{\circ}$ & $23.05^{\circ}$ & 351535 & $1956-2008$ \\
15 & Minjiang River & Zhuqi & $119.10^{\circ}$ & $26.15^{\circ}$ & 54500 & $1956-2008$ \\
\hline
\end{tabular}

Table 2. Statistical features of the VIC model parameters for 125 calibrated catchments.

\begin{tabular}{cllll}
\hline Parameter & Physical interpretation & Maximum & Minimum & Mean \\
\hline B & Exponent of variable infiltration curve & 0.37 & 0.02 & 0.26 \\
$D_{m}$ & Maximum daily base flow (mm) & 1.2 & 31 & 17.2 \\
$D_{s}$ & Fraction of $D_{m}$ in which non-linear base flow occurs & 0.2 & 0.01 & 0.11 \\
$W_{S}$ & Fraction of maximum soil moisture in the lower soil & 0.9 & 0.6 & 0.82 \\
& layer for which nonlinear base flow occurs & & & \\
$d_{1}$ & Thickness of the first soil layer (m) & 1.5 & 0.1 & 0.07 \\
$d_{2}$ & Thickness of the second soil layer (m) & 1.5 & 0.2 & 0.7 \\
$d_{3}$ & Thickness of the third soil layer (m) & & 0.8 \\
\hline
\end{tabular}

\section{Results and discussion}

\subsection{Discharge simulation and regional parameterization}

There are seven hydrological parameters in the VIC model that need to be calibrated with recorded daily stream flow. Previous studies have documented how flows in some of the major rivers in north China have been strongly influenced by intensive human activities since the late 1970s (Xu, 2009; Wang, 2001). In order to eliminate the effects of human activity on runoff, data from 1961-1980 were therefore used to calibrate the model. Thus, the calibrated model parameters should reflect the situation prior to major abstractions and other human influences throughout the basin. Data series were divided into two periods: a period from 1961 to 1975 for model calibration, and a period from 1976 to 1980 for model validation. The simulation results for each subcatchment, described using the Nash and Sutcliffe efficiency criterion (NSE) and relative error (RE), are illustrated in Figs. 2 and 3, respectively.
Figures 2 and 3 show that the VIC model performs well, in general, for each catchment. NSEs range from $68.2 \%$ to $93.3 \%$ for the calibration period and $61.6 \%$ to $92.4 \%$ for the verification period. REs for both periods fall in a small range of $-7.1 \%$ to $+8.2 \%$, with more than $80 \%$ of REs falling in the range $\pm 5 \%$.

Hydrological model parameters reflect the hydrological features of a catchment, which are determined to some extent by climate conditions and soil texture. Statistics for calibrated parameters of the VIC model in 125 selected catchments are given in Table 2.

As shown in Table 2, there are four dimensional parameters and three non-dimensional parameters in the VIC model. In general, the spatial distributions of the thicknesses of the three soil layers are in accordance with the distribution of soil type and texture, with higher values occurring in the Jianghuai plain, the Tibetan plateau and north China, and lower values in the Sichuan basin, the Yungui plateau and south China. $D_{m}$ varies greatly across space with higher values in humid areas and cold areas, and lower values in dry areas. $W_{s}$ and $B$ range from $0.6-0.9$ and $0.02-0.37$, respectively; their spatial distribution is generally similar to that 


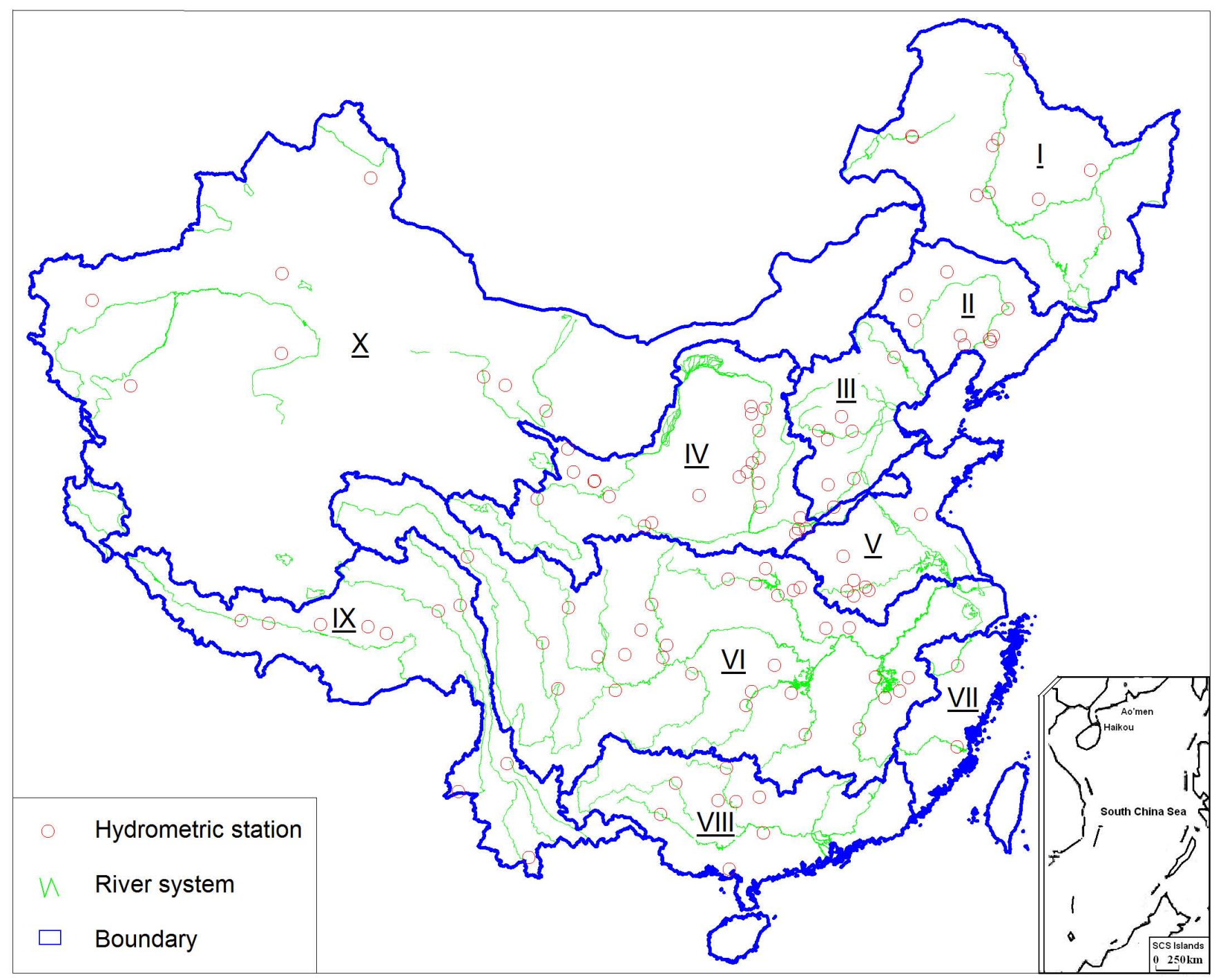

Fig. 1. Major river systems in China and locations of sub-catchments for model calibration.

of $D_{m} . D_{s}$ is not as sensitive as other parameters, with the highest value occurring in northwest China and lower values in other regions.

As the calibrated catchments comprise all types of soil texture, to model any objective grid cell outside the calibrated catchments, we selected the most similar calibrated catchment, defined as the nearest catchment with the same dominant soil type. The calibrated hydrological parameters of the most similar catchment were then transferred to the objective grid cell not covered by the calibrated catchments. In order to test the performance of the VIC model in large-scale hydrological simulations with transferred parameter values, we statistically compared the simulated and recorded runoffs at 15 key hydrometric stations on major rivers (Table 3 ). The simulated and recorded runoffs for 1961-1980 at the Beipei hydrometric station in southern China and at the Tangnaihai hydrometric station in northwest China are graphed in Figs. 4 and 5 , respectively.

Figures 4 and 5 show that simulated and recorded runoff closely match for both stations, with about $6.4 \%$ overestimation of low flow on average during the dry season, and about $4.8 \%$ underestimation of peak flow during the flood season. NSEs for both stations exceed $90 \%$, with relative errors of volumetric fit of less than $5 \%$. Statistical results for monthly discharge simulations at all 15 hydrometric stations on major rivers in China also indicate close correspondence between mean simulated and recorded annual runoff, with relative errors in the water balance of less than $7 \%$, whilst NSEs are all above $70 \%$ (Table 3). The transfer of calibrated parameter values to ungauged areas appears to work well in this instance, suggesting that the VIC model accurately simulates runoff across China. 
Table 3. Results of simulation of monthly discharges at 15 key hydrometric stations on major rivers in China.

\begin{tabular}{cllrrrr}
\hline No. & River & Gauging site & Area $\left(\mathrm{km}^{2}\right)$ & NSE $(\%)$ & RE $(\%)$ & Data series \\
\hline 1 & Songhuajiang River & Yilan & 491706 & 78.5 & -2.7 & $1956-2008$ \\
2 & Songhuajiang River & Ha'erbin & 389769 & 85.1 & 0.8 & $1956-2008$ \\
3 & Liaohe River & Tieling & 120764 & 84.8 & 3.6 & $1956-1969$ \\
4 & Haihe river & Luanxian & 44100 & 72.6 & 6.3 & $1956-1969$ \\
5 & Haihe River & Shixiali & 23627 & 74.9 & 3.2 & $1956-1969$ \\
6 & Yellow River & Lanzhou & 229224 & 85.2 & 1.2 & $1956-1969$ \\
7 & Yellow River & Huaxian & 106498 & 77.8 & 2.4 & $1956-1969$ \\
8 & Huaihe River & Wangjiaba & 30630 & 88.3 & -2.9 & $1956-2008$ \\
9 & Huaihe River & Wujiadu & 121330 & 81.2 & 1.6 & $1956-2008$ \\
10 & Yangtze River & Shigu & 244489 & 91.7 & 0.4 & $1956-2008$ \\
11 & Yangtze River & Beipei & 156142 & 92.3 & -3.7 & $1956-2008$ \\
12 & Yangtze River & Huangzhuang & 142056 & 87.4 & -0.1 & $1956-2008$ \\
13 & Pearl River & Tian'e & 105535 & 94.2 & 0.7 & $1956-2008$ \\
14 & Pearl River & Gaoyao & 351535 & 90.8 & -0.1 & $1956-2008$ \\
15 & Minjiang River & Zhuqi & 54500 & 96.5 & 1.4 & $1956-2008$ \\
\hline
\end{tabular}

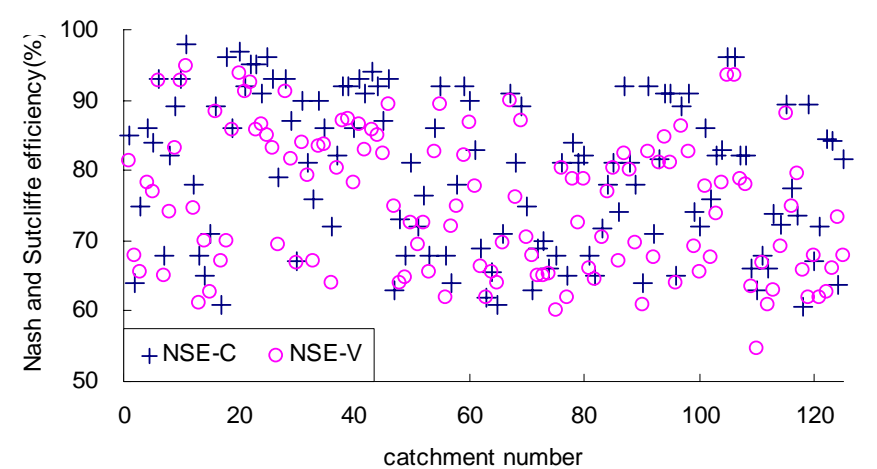

Fig. 2. Nash and Sutcliffe efficiency criterion for each subcatchment in the calibration period and validation period (NSE-C: Nash and Sutcliffe efficiency criterion in calibration period, NSE-V: Nash and Sutcliffe efficiency criterion in validation period).

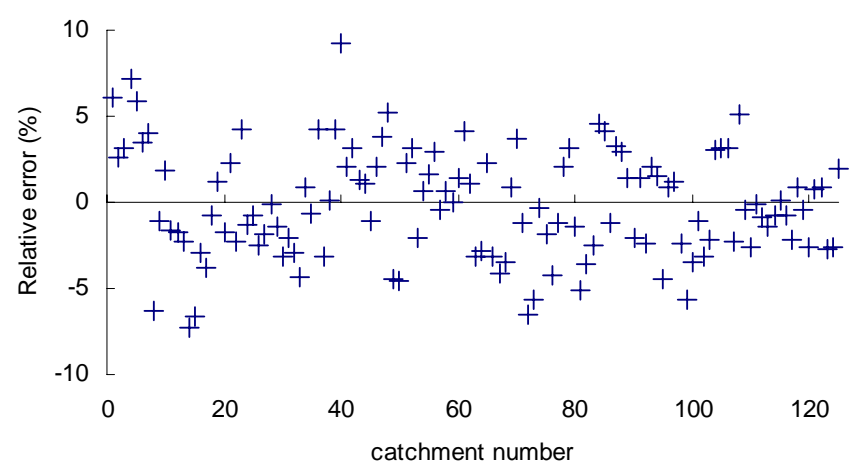

Fig. 3. Relative error of volumetric fit for each site.

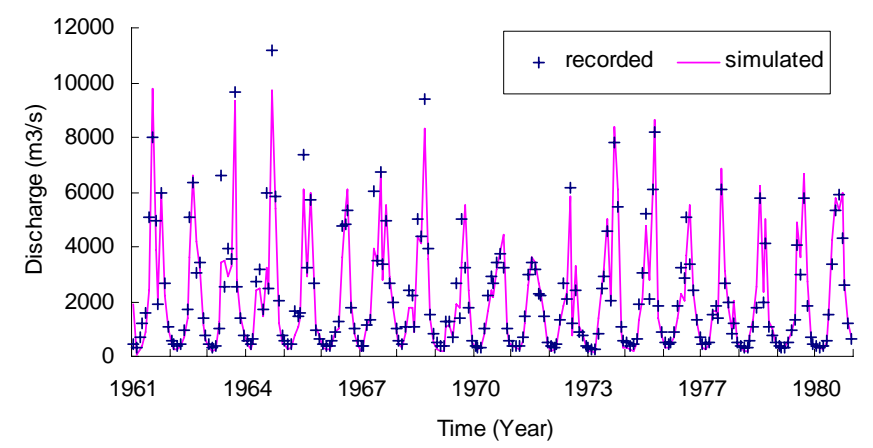

Fig. 4. Recorded and simulated monthly discharges at the Tangnaihai station in the Yellow River basin, with a drainage area of $121972 \mathrm{~km}^{2}(\mathrm{NSE}=90.1 \%, \mathrm{RE}=-4.2 \%)$.

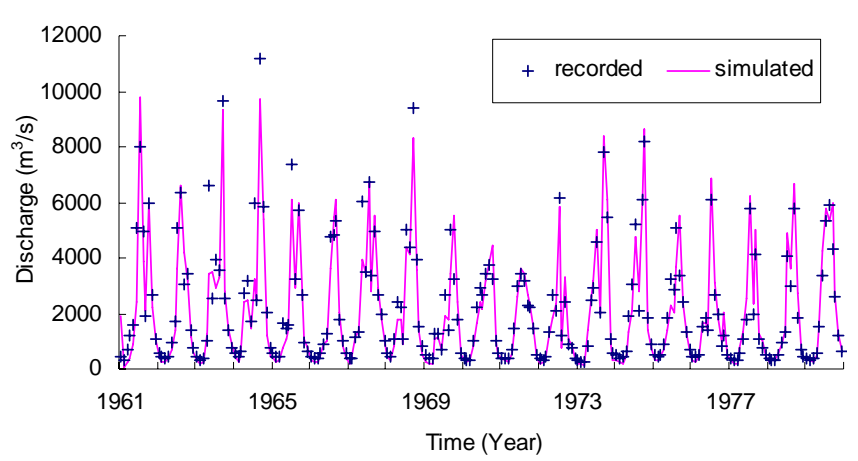

Fig. 5. Recorded and simulated monthly discharges at the Beipei station in the Yangtze River basin, with a drainage area of $156142 \mathrm{~km}^{2}(\mathrm{NSE}=92.4 \%, \mathrm{RE}=-3.7 \%)$. 


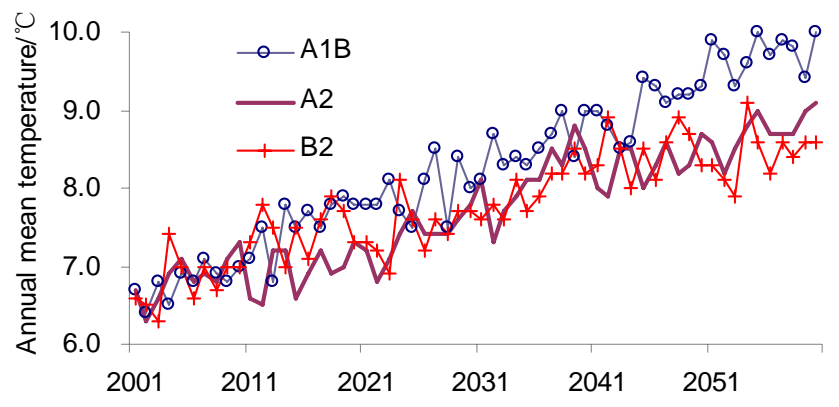

Fig. 6. Projected annual mean air temperature over China under emissions scenarios A1B, A2 and B2.

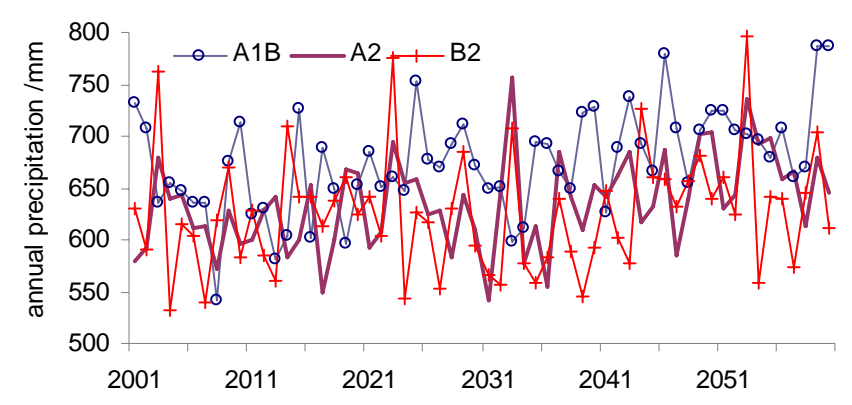

Fig. 7. Projected annual precipitation over China under emission scenarios A1B, A2 and B2.

\subsection{Climate change scenarios for the next $50 \mathrm{yr}$}

$\mathrm{Xu}$ et al. (2005) and Zhang et al. (2006) used the Hadley Centre RCM system-PRECIS (Providing Regional Climates for Impacts Studies, PRECIS) model to analyze changes in temperature and precipitation over the whole of China under SRES (Special Report on Emission Scenarios) scenarios A2, B2 and A1B in the 21 st century. Financially supported by the ACCC project (Adapting Climate Change in China), Xu et al. improved the RCM-PRECIS model to project climate change with a resolution of $0.5^{\circ} \times 0.5^{\circ}$, consistent with the resolution of the VIC model. The projected country-averaged annual air temperature and the projected annual precipitation over China under these emissions scenarios are shown in Figs. 6 and 7 , respectively.

Figures 6 indicates that projected annual mean air temperatures under the three emission scenarios rise steadily at an annual average rate of approximately $0.045^{\circ}$, with the highest rate being $0.055^{\circ}$ annum ${ }^{-1}$ under scenario A1B, much higher than previous rates cited by the IPCC (IPCC, 2007). Figure 7 indicates that annual precipitation is expected to rise slightly, with high variability (from $530 \mathrm{~mm}$ to $790 \mathrm{~mm}$ annum $^{-1}$ ). On average, projected annual precipitation for the period 2021-2050 increases by $2.1 \%-8.7 \%$ compared with the 19610-1990 baseline.

China's climate varies significantly over time and space because of the influence of topography and monsoon con- ditions. Projections indicate a significant warming trend across China for the period 2021-2050, with the largest temperature increases being $1.58^{\circ}-2.25^{\circ}$ for the Songhuajiang River basin and $1.63^{\circ}-2.25^{\circ}$ for the northwestern part of China. The trend of increasing rainfall over this period is particularly pronounced in southeast China, the Liaohe River basin and northwest China, with increases of 5\%-11.2\%, $3.6 \%-15.4 \%$ and $4.8 \%-13.7 \%$, respectively, compared to the 1961-1990 baseline. Drying will probably occur in the Yellow River basin and central China.

\subsection{Water resource scenarios for the next $50 \mathrm{yr}$}

China is divided into ten major water regions, including the Songhuajiang River basin, the Liaohe River basin, the Haihe River basin, the Yellow River basin, the Huaihe River basin, the Yangtze River basin and the Pearl River region (Fig. 1). Based on estimations of synchronous runoff data for a 50-yr period from 1956-2005, mean annual runoff for China as a whole is $2712 \times 10^{9} \mathrm{~m}^{3}$, equivalent to a mean runoff depth of $284 \mathrm{~mm}$. More than $70 \%$ of total runoff occurs in the flood season from June to October in most areas. South China to the Yangtze River accounts for $36.5 \%$ of the geographical area, but has as much as $81 \%$ of total water resources.

The calibrated VIC model was run on 4160 grid cells continuously from 1961-2050 to estimate runoff at each cell given the climate projections of RCM-PRECIS under SRES emission scenarios A2, B2, and A1B. Taking simulated runoff in the period 1961-1990 as a baseline, we statistically analyzed changes in runoff for the period 2021-2050 in the ten drainage basins listed above (Table 4).

Table 4 shows that different scenarios are associated with different changes in annual runoff over China. Scenario A1B leads to the greatest increases in runoff, with increases in all areas of China except the Yellow River basin, an average increase of $11.3 \%$ for China as a whole, a $2.1 \%$ decrease in the Yellow River basin and a maximum increase of $20.8 \%$, occurring in the Liaohe River basin. Scenario A2 gives qualitatively similar results except in the Songhuajiang River basin, where a $4 \%$ decrease in annual runoff is projected. Under scenario B2, annual runoff is projected to decline in most areas of northern China, with a maximum decrease of $10.8 \%$ in the Songhuajiang basin.

Changes in runoff during the flood season from June to September, show similar but more pronounced trends (Table 4). Under scenario A1B, runoff decreases in the Yellow River basin, while other regions experience increases over the same period. Under scenario A2, three regions - the Songhuajiang river basin, the Yellow River basin and northwest China - experience decreasing runoff during the flood season, with the greatest change (a reduction of $7.7 \%$ ) in the Yellow River basin. The model shows other regions experiencing an increase in runoff, with the greatest change (an $11.4 \%$ increase) in southeast China. 

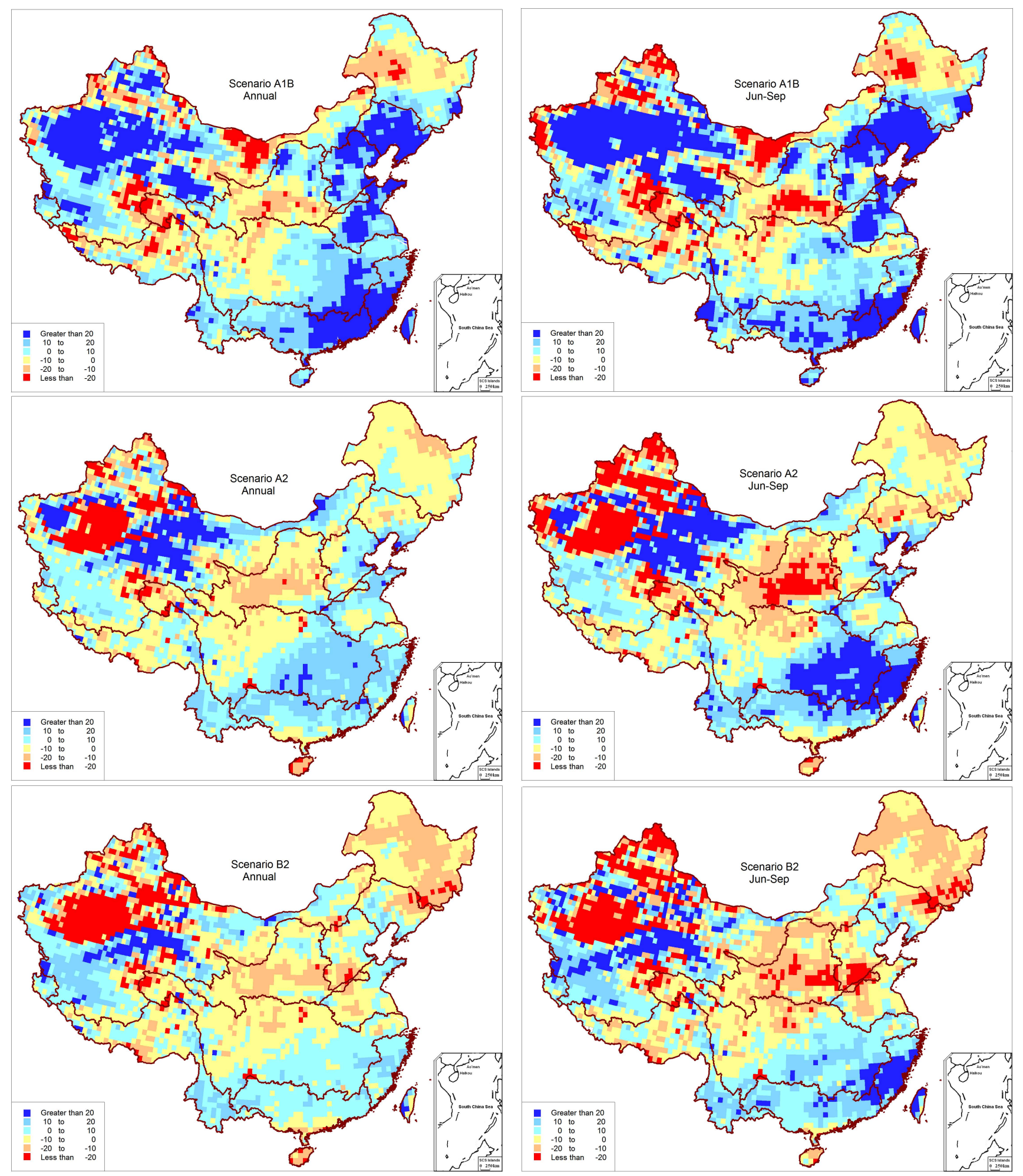

Fig. 8. Distribution of projected average runoff changes, for whole year (annual) and flood season from June to September, in 2021-2050 under A1B, A2 and B2 scenarios (baseline: 1961-1990). 
Table 4. Changes in runoff for 2021-2050 under scenarios A1B, A2 and B2.

\begin{tabular}{c|l|l|lr|rrr}
\hline No. & River basin & \multicolumn{3}{|c|}{ Changes in annual runoff $(\%)$} & \multicolumn{2}{r}{ Runoff change in Jun-Sep (\%) } \\
\hline & & A2 & B2 & A1B & A2 & B2 & A1B \\
I & Songhuajiang River basin & -4.0 & -10.8 & 1.1 & -5.5 & -11.7 & 1.4 \\
II & Liaohe River basin & 2.6 & -6.4 & 20.8 & 1.5 & -7.4 & 21.4 \\
III & Haihe River basin & 5.2 & -3.3 & 11.3 & 3.3 & -7.7 & 10.3 \\
IV & Yellow River basin & -4.1 & -6.4 & -2.1 & -7.7 & -10.8 & -4.2 \\
V & Huaihe River basin & 6.0 & -1.2 & 12.9 & 6.1 & -3.1 & 10.5 \\
VI & Yangtze River basin & 6.6 & 0.7 & 8.2 & 8.2 & 3.1 & 4.2 \\
VII & Region of southeast China & 9.1 & 8.3 & 13.2 & 11.4 & 12.0 & 12.3 \\
VIII & Pearl River basin & 0.9 & -3.0 & 11.8 & 0.5 & 1.1 & 10.1 \\
IX & Region of southwest China & 0.8 & 0.3 & 3.6 & 0.7 & -0.4 & 4.6 \\
X & Region of northwest China & 0.2 & 2.4 & 2.6 & -0.9 & 2.4 & 0.6 \\
& China as a whole & 2.9 & -0.7 & 11.3 & 3.4 & 0.9 & 9.1 \\
\hline
\end{tabular}

Over China as a whole, with the exception of a $0.7 \%$ decrease in annual runoff under scenario B2, annual runoff is projected to increase by between $2.9 \%$ and $11.3 \%$, with flood-season runoff increasing by between $0.9 \%$ and $9.1 \%$.

Shown in Fig. 8 are the spatial distributions of changes between the baseline and 2021-2050 in average runoff annually and during flood season (June to September), under the A1B, A2 and B2 scenarios. The figure shows that the projected changes in annual and flood-season patterns are generally similar for a same scenario, but that changes are greater under scenario A1B compared to scenarios A2 and B2. Under all three scenarios, runoff will increase in southeast China, and decrease in most of the northeast and central areas, particularly in the Yellow River basin. Although increases in runoff are projected for most of the northwest under A1B, the opposite occurs under A2 and B2. The existing pattern of "north dry and south wet" will likely be exacerbated under global warming.

Although we present likely trends for changes in runoff, these projections of future water resources carry high uncertainty due to uncertainties in emission scenarios, in the outputs from GCMs, in downscaling approaches and in the assessment model itself. The issue of uncertainty should therefore be addressed in further studies.

\section{Summary and conclusions}

Our VIC model, with a resolution of $50 \times 50 \mathrm{~km}^{2}$, was calibrated with 125 well-gauged catchments. Based on similarities in climate conditions, soil texture and other properties, model parameters were transferred to ungauged areas. The VIC model simulates monthly discharge well in catchments of various sizes, indicating that parameter transfer based on hydrological similarity is a feasible way of implementing regional parameterization of the VIC model across China.

Model results for runoff across China differ depending on the SRES scenario used. In general, southeast China may experience greater rainfall and runoff in the coming decades, while central China is likely to face greater water scarcity. The pattern of "north dry and south wet" will probably be exacerbated.

Although changes in projected runoff are uncertain, regional water shortages and regional flooding remain key issues that are likely to grow in importance. Climate change will add to the challenges of water resource management by introducing greater variability in water systems and changing flow conditions in surface water systems, amplifying existing patterns of shortage and excess. Effective adaptation strategies will be needed to respond to these trends and safeguard economic growth and poverty reduction efforts under the 12 th five-year plan.

Acknowledgements. This study has been financially supported by the National Basic Research Program of China (grant 2010CB951103), the International Science \& Technology Cooperation Program of China (grant 2010DFA24330) and the ACCC (Adapting Climate Change in China) project funded by DFID, SDC and DECC. Thanks also to the anonymous reviewers and editors.

Edited by: E. Toth

\section{References}

Arnell, N. W.: A simple water balance model for the simulation of stream flow over a large geographic domain, J. Hydrol, 217, 314-355, 1999.

Loukas, A. and Quick, C. M.: Effect of climate change on hydrological regime of two climatically different watersheds, J. Hydrol. Eng., 2, 77-87, 1996.

Cosby, B. J.: A statistical exploration of the relationships of soil moisture characteristics to the physical properties of soils, Water Resour. Res., 20, 682-697, 1984.

Ding, Y. H. and Ren, G. Y.: National assessment report of climate change (I): Climate change and its future trend, (in Chinese with English abstract) Adv. Climate Change Res., 2, 1-8, 2006 
Fu, G. B., Michael, E. B., and Chen, S. L.: Impacts of climate change on regional hydrological regimes in the Spokane River Watershed, J. Hydrol. Eng., 12, 452-461, 2007.

Gleick, P. H.: The development and testing of a water balance model for climate impact assessment: modeling the Sacramento basin, Water Resour. 23, 267-282, 1987.

Habets, F.: The ISBA surface scheme in a macroscale hydrological model applied to the Hapex-Mobilhy area - Part I: Model and database, J. Hydrol., 217, 75-89, 1999.

Hans, T.: The influence of climate change on stream flow in Danish rivers, J. Hydrol., 333, 226-238, 2007

Huntington, T. G.: Climate warming could reduce runoff significantly in New England, USA, Agr. Forest Meteorol., 117, 193201, 2003

IPCC.: Climate Change 2007: The Physical Science Basis, Cambridge University Press, Cambridge, UK, 156-178, 2007.

IPCC.: Climate Change and Water, Cambridge University Press, Cambridge, UK and New York, USA, 65-87, 2008.

Kiem, A. S. and Verdon, D. C.: Steps toward "useful" hydroclimatic scenarios for water resource management in the Murray Darling Basin, Water Resour. Res., 47, W00G06, doi:10.1029/2010WR009803, 2011.

Kundzewicz, Z. W. and Stakhiv, E. Z.: Are climate models "ready for prime time" in water resources management applications, or is more research needed?, Hydrol. Sci. J., 55, 1085-1089, 2010.

Li, L., Hao, Z. C., Wang, J. H., Wang, Z. H., and Yu, Z. B.: Impact of future climate change on runoff in the head region of the Yellow River, J. Hydrol Eng., 13, 347-354, 2008.

Liang, X. and Xie, Z.: A new surface runoff parameterization with subgrid-scale soil heterogeneity for land surface model, Adv. Water Res., 24, 173-193, 2001.

Liang, X., Lettenmaier, D. P., and Wood, E. F.: A simple hydrological model of land surface water and energy fluxes for general circulation models, J. Geophys., 99, 14415-14428, 1994.

Lohmann, D., Raschke, E., and Nijssen, B.: Regional scale hydrology - I: Formulation of the VIC-2L model coupled to a routing model, Hydrol. Sci. J., 43, 131-141, 1998.

Lu, G. H., Wu, Z. Y., and He, H.: Processes of Hydrological Cycle and Quantitative Forecasting, (In Chinese), Science Press, Beijing, China, 2010.

Nash, J. E. and Sutcliffe, J.: River flow forecasting through conceptual models: Part 1 - A discussion of principles, J. Hydrol., 10, 282-290, 1970.
Rawls, W. and Yates, P.: Calibration of Selected Infiltration Equations for the Georgia Coastal Plain, US Department of Agriculture, Agricultural Research Service, Washington DC, USA, 113, 121-134, 1976.

Roger, N., Francis, H. S., Walter, C., and Zhang, L.: Estimating the sensitivity of mean annual runoff to climate change using selected hydrological models, Adv. Water Resour., 29, 1419-1429, 2005.

Wang, G. Q., Jia, X. A., Chen, J. N., Zhang, Y., Li, H. B., and Wang, Y. Z.: Analysis on the transition point of hydrological series impacted by human activities - a case study of Wudinghe basin in the middle reaches of the Yellow River, J. Water Res. Water Eng., 12, 13-15, 2001.

Wang, W. C., Chau, K. W., Cheng, C. T. and Qiu, L.: A comparison of performance of several artificial intelligence methods for forecasting monthly discharge time series, J. Hydrol, 374, 294-306, 2009.

Xie, Z. H., Yuan, F., Duan, Q. Y., Zheng, J., Liang, M. L., and Chen, F.: Regional Parameter Estimation of the VIC Land Surface Model: Methodology and Application to River Basins in China, J. Hydrometeorol, 8, 447-468, 2007.

Xu, J. H., Li, X. Y., Chen, J. J., Gao, Y. J., and Li, M.: Impact of Water Conservancy Projects on Storm Flood and Sediment Yield in the Middle Reaches of the Yellow River, Yellow River Press, Zhengzhou, China, 2009.

Xu, Y. L., Huang, X. Y., and Zhang, Y.: Statistical analyses of climate change scenarios over China in the 21 st century, Adv. Clim. Change Res., 1, 80-83, 2005

Zhang, J. Y. and Wang, G. Q.: Impacts of Climate Change on Hydrology and Water Resources. Science Press, (In Chinese), Beijing, China, 7-112, 2007.

Zhang, J. Y., Wang, G. Q., He, R. M., and Liu, C. S.: Variation trends of runoffs in the Middle Yellow River basin and its response to climate change, (In Chinese with an English abstract), Adv. Water Sci., 20, 153-158, 2009.

Zhang, Y., Xu, Y. L., and Dong, W. J.: A future climate scenario of regional changes in extreme climate events over China using the PRECIS climate model, Geophys. Res. Lett., 33, L24702, doi:10.1029/2006GL027229, 2006. 